\title{
РАЗГРАНИЧЕНИЕ КОМПЕТЕНЦИИ МЕЖДУ ПУБЛИЧНО-ПРАВОВЫМИ ОБРАЗОВАНИЯМИ КАК ОСНОВА РАЗГРАНИЧЕНИЯ БЮДЖЕТНЫХ РАСХОДОВ
}

\author{
(c) 2021 Бабина Ксения Ивановна \\ кандидат юридический наук,
} доцент кафедры «Государственное правое регулирование экономики и кадровой политики» Саратовский государственный технический университет имени Ю. А. Гагарина, Россия, Саратов E-mail:ks.03.90@mail.ru

\section{(c) 2021 Бехер Вероника Виссарионовна}

кандидат юридический наук, доцент,

заведующий кафедрой «Государственное правое регулирование экономики и кадровой политики» Саратовский государственный технический университет имени Ю. А. Гагарина, Россия, Саратов E-mail: bekher@mail.ru

На сегодняшний день существуют проблемы эффективного расходования бюджетных средств, которые вызваны отсутствием рациональных начал использования бюджетных средств публичноправовыми образованиями. Автор приходит к выводу о том, что существующая бюджетная система РФ формировалась в условиях интенсивного влияния как советского типа функционирования бюджетной системы, так и европейского интеграционного опыта в бюджетном «строительстве». Вся система распределения полномочий между центром и территориальными единицами строится на принципе «бюджетного федерализма», что в условиях существующего федеративного типа государства РФ наиболее логично и эффективно.

Ключевые слова: расходы бюджета, публично-правовые образования, компетенции, распределение.

Разграничение компетенции между территориальными субъектами подразумевают разграничение расходных обязательств между различными уровнями власти и местного самоуправления, что в свою очередь обусловливает распределение расходной части консолидированного бюджета страны между публичноправовыми образованиями.

В настоящее время остро встает вопрос разграничения бюджетной компетенции между органами государственной власти федерального и регионального уровня, а также органами местного самоуправления. В свете этого наиболее актуальной проблемой является проблема распределения расходной части консолидированного бюджета между федеральным уровнем власти, его территориальными единицами и местным самоуправлением.

Российская Федерация, образовывавшаяся после развала СССР в 1991 году, провозгласила себя государством федеративного типа. Это послужило отправной точкой для возникновения и развития новой бюджетной системы, построенной на принципах разграничения бюджетных полномочий между уровнями власти.

Актуальность вопроса распределения ком- петенции непосредственным образом связана с тем, что современная модель бюджетной системы формировалась под воздействием системы, существовавшей в советское время.

До 1991 года вопросы полномочий публичноправовых образований не только в сфере расходной части бюджета, но и по всему спектру бюджетных правоотношений строился на основании принципов единства и демократического централизма, которые были закреплены в нормативно-правовых актах СССР и союзных публично-правовых образованиях. Принцип демократического централизма предполагал комбинации централизованного управления бюджетной системой СССР из единого центра с передачей некоторых бюджетных прав союзным республикам и местным административнотерриториальным единицам.

Таким образом, длительный процесс развития российской бюджетной системы и вопросы полномочий центра и субъектов РФ протекал в условиях сильного влияния механизмов и моделей, сформированных еще в советской системе координат, которые ориентировались на другие цели и задачи, несли в себе иное экономическое и идеологическое содержание. 
Сохраняя в себе черты советской системы бюджетного строительства, Российская Федерация, тем не менее, начала внедрять в свое правовое поле институты, свойственные западной модели распределения компетенции между территориальными субъектами, тем самым меняя сам механизм распределения расходов.

В архитектуру бюджетной системе РФ имплементированы институты и модели, касающиеся сферы расходования бюджетных средств, свойственные таким типам федеративных бюджетных систем, как Швейцария и ФРГ.

Например, общий объем расходов и соответственно система полномочий государственнотерриториальных образований в Швейцарии во многом идентичен современной российской бюджетной системе. Так, расходы бюджета распределяются между коммунами, кантонами и конфедерацией. Однако, отличительным признаком швейцарской модели, который, к сожалению, не стал свойственен российской бюджетной системе, является закрепление большинства расходов, связанных с социальноэкономической жизнью (культура, образование, спорт, коммунальное хозяйство и др.) за кантонами и коммунами, которые, в отличии от существующей в России проблемы недостаточного финансирования расходных обязательств субъектов и муниципалитетов, таким финансированием из доходной части своих бюджетов располагают. Расходные обязательства в сфере обороны, международные отношения (92\% от общей суммы расходной части консолидированного бюджета), транспорта, экономики (52\%) возлагаются на правительство [4, с.526].

Так объем расходов по социальноэкономическим вопросам, который финансируется не из конфедеративного бюджета, а из бюджета кантонов и коммун, составляет около $65 \%$ от общего числа бюджетных расходов на эту статью бюджета [5, с.73].

Таким образом, в Швейцарии не только отсутствует большая потребность вертикального бюджетного выравнивания, но и значительно ниже зависимость региональных бюджетов от федерального центра, чем в других странах. Данный опыт мог бы быть полезен при грядущем реформировании отечественной системы института компетенции публично-правовых образований в сфере расходных обязательств.

Немаловажным для всего бюджетного процесса являлось присоединение РФ в 1998 году к
Европейской хартии местного самоуправления (далее - Хартия). Данный документ содержит не только основополагающие принципы построения бюджетных отношений с участием органов местного самоуправления, но и декларирует распределение конкретных полномочий по расходованию бюджетных средств между различными уровнями власти.

Согласно п. 1 статьи 9 Хартии предусматривается, что «самоуправляющиеся территориальные общности имеют право в рамках национальной экономической политики претендовать на соответствующие собственные средства, которыми они могут свободно распоряжаться для осуществления своих полномочий» [1]. Тем самым прослеживается декларирование территориального распределения полномочий между публично-правовыми образованиями как основу распределения расходных обязательств.

Данная проблематика тесно связано с такой известной и проработанной теоретиками бюджетного права категорией как «бюджетный федерализм».

Термин «бюджетный федерализм» легально не закреплен в законодательстве РФ, однако в проекте Бюджетного кодекса РФ содержалась дефиниция данной категории. В ней указывалось, что бюджетный федерализм есть отношения между органами государственной власти РФ и органами государственной власти субъектов РФ по поводу разграничения бюджетных полномочий, расходов и доходов, их распределение и перераспределение между федеральным бюджетом и консолидированными бюджетами субъектов РФ, исходя из сочетания общегосударственных интересов населения, проживающего на территории субъектов РФ и входящих в них муниципальных образований [6, с.42].

Нужно обратить внимание, что в данном определении органы местного самоуправления не выступают в качестве субъектов данного отношения. Указывается лишь на население, проживающее на территории муниципальных образований, входящих в субъект РФ. Законодатель, изъяв из проекта данную статью и определение бюджетного федерализма, стремился не допустить принятие кодекса с юридически спорными нормами-дефинициями, что совершенно логично. Однако полное изъятие легального определения данного понятие думается, также является ошибочным, так как данная категория является настолько многоаспектной и 
содержательной, что при ее отсутствии возникает проблемы эффективного и перспективного развития бюджетной системы РФ как системы федеративного типа.

В отечественной юридической науке единого подхода к формированию определения данной категории также не существует. Профессор Ю.А. Крохина определяет ее как процесс территориального перераспределения бюджетных средств [7, с.40], А.М.Лавров- как совокупность основополагающих начал и способов осуществления налогово-бюджетных отношений между отельными уровнями государственной власти [8, c.18].

Таким образом, можно сделать вывод об отсутствии в российской юридической доктрине теории выделения самостоятельного муниципального уровня, как независимой структурной единицы, входящей в понятие принципа бюджетного федерализма.

Анализируя вышеуказанные позиции авторов, можно говорить о следующем определении. Бюджетный федерализм - это совокупность бюджетно-правовых отношений, возникающих между различными уровнями власти, регламентированные нормами бюджетного законодательства и позволяющие соответствующему уровню власти реализовывать бюджетные полномочия в рамках закрепленной за ним компетенции.

Территориальное разграничение расходов, или классификация расходов по признаку принадлежности, основывается на установлении ответственности разных уровней публичной власти за выполнение конкретно-установленных законом задач. Государственные расходы общего характера (централизованные расходы) исполняются органами федерального уровня государственного управления, возлагаются на федеральный бюджет. Исполнение иных задач закрепляется за уровнем субъектов РФ, а задачи местного значения - за органами местного самоуправления.

Существует мнение, что наиболее рациональным для выполнения функций органов власти различного уровня путем расходования бюджетных средств является их соответствие сферы территориальной потребности всего государства или отдельных его субъектов.

Согласно статьям 71-73 Конституции РФ в РФ предусмотрен территориальный признак распределения расходов в соответствии с кон- ституционными положениями о предметах ведения РФ и субъектов РФ.

Конкретизирует данные положения статья 65 Бюджетного кодекса РФ, предусматривающая, что «формирование расходов бюджетной системы Российской Федерации осуществляется в соответствии с расходными обязательствами, обусловленными установленным законодательством Российской Федерации разграничением полномочий федеральных органов государственной власти, органов государственной власти субъектов Российской Федерации и органов местного самоуправления».

Современное бюджетное право предполагает соотнесение распределения расходов бюджета, привязанному к территориальному компоненту, с категорией «расходное обязательство бюджета» [2].

Определенное расходное обязательство возлагается только на соответствующее публичноправовое образование и исполняется им самостоятельно. Принадлежность расходного обязательства определяется субъектом принятия нормативно-правового акта или заключения контракта, предполагающий конкретное расходное обязательство. Расходные обязательства не передаются, не допускается установление одного расходного обязательства одновременно несколькими публично-правовыми образованиями.

Разграничение полномочий по финансированию расходных обязательств, относящихся к предметам совместного ведения Российской Федерации и субъектов Российской Федерации, установлено также Федеральным законом от 6 октября 1999 г. № 184-ФЗ «Об общих принципах организации законодательных (представительных) и исполнительных органов государственной власти субъектов Российской Федерации». Этим же Законом установлено, что полномочия Российской Федерации по предметам ее ведения, а также полномочия по предметам совместного ведения Российской Федерации и ее субъектов могут передаваться последним для осуществления на основании федеральных законов [3]. Финансовое обеспечение переданных таким образом полномочий осуществляется за счет субвенций из федерального бюджета или бюджетов государственных внебюджетных фондов Российской Федерации. Аналогичный порядок установлен для отношений между бюджетами субъектов Российской Федерации и местными 


\section{бюджетами.}

Таким образом, опираясь на вышеизложенное, можно констатировать несколько выводов, касающихся разграничения компетенции между территориальными субъектами как основу разграничения бюджетных расходов:

1. Существующая бюджетная система РФ, включающая кластер институтов, связанных с расходной частью бюджетных обязательств публично-правовых образований, формирова- лась в условиях интенсивного влияния как советского типа функционирования бюджетной системы, так и европейского интеграционного опыта в бюджетном «строительстве».

2. Расходные обязательства РФ и территориальных единиц конкретно поименованы в Бюджетном кодексе РФ, а также в иных нормативно-правовых актах, затрагивающих сферу компетенции публично-правового образования в институте расходных обязательств.

\section{Библиографический список}

1. Европейская хартия местного самоуправления (совершено в Старсбурге 15.10.1985 г.) //С3 РФ. 1998. № 36, ст. 4466.

2. Бюджетный кодекс Российской Федерации от 31 июля 1998 г. № 145-Ф3 (с изм. от 15 октября 2020 г.) // С3 РФ. 1998. № 31 ст. 3823.

3. Федеральный закон от 06.10.1999 № 184-Ф3 «Об общих принципах организации законодательных (представительных) и исполнительных органов государственной власти субъектов Российской Федерации» (с изм. от 13.07.2020 г.) // СЗ РФ.1999. № 42, ст. 5005.

4. A. Baranzini, Structures et coûts des stations d'épuration en Suisse et gestion efficace des eaux usées, Swiss Journal of Economics and Statistics, 1996, 4/1, P. 526.

5. B. Dafflon, «Fiscal Federalism in Switzerland», in FOSSATI A. and PANELLA G., Fiscal Federalism in Europe, Routledge Studies in the European Economy, 2005, London, P. 73.

6. Бочкарева Е.А.Сбалансированная бюджетная система: финансово-правовое исследование: монография. Краснодар, ОИПЦ «Перспективы образования», 2013. С. 42.

7. Крохина Ю.А. Бюджетное право и российский федерализм / Под ред. проф. Н.И. Химичевой. М., Издательство НОРМА, 2001.- - С. 40.

8. Лавров А. М. Межбюджетные отношения и финансовая стабилизация // ЭКО. 1995. № 9 С. 18. 